\title{
The effect of fertigation on salinization and stability of soil aggregates, taking into account the effectiveness of precipitation on their natural desalination in central Europe
}

\author{
Bulat Ziganshin, Ilgiz Galiev, Rail Khusainov*, and Ahmed Abdelfattah
}

Kazan State Agrarian University, 420015 Kazan, Russia

\begin{abstract}
The effect of fertigation on the physicochemical properties of soil was estimated. Three fertigation procedures with different salinity levels were tested. The effect of precipitation on soil desalination through salt leaching was controlled by comparing changes in soil electrical conductivity during and after vegetation. Soil aggregate stability was measured as an indicator of soil degradation. The electrical conductivity of soil during pre-sowing (or after sowing) treatment was higher than at the end of the growing season. This difference decreased significantly, becoming insignificant after winter due to the effective dissolving effect of rain and snow. The article considers the issues of natural soil desalination, taking into account precipitation. Studies of soil desalination by leaching of salts were described. It was revealed that in the short term fertigation is not harmful to the soil if the amount of precipitation is sufficient.
\end{abstract}

\section{Introduction}

Irrigation water is a major limiting factor for agricultural production. Irrigated lands produce more than $40 \%$ of food and provide nearly $80 \%$ of water consumed. In addition, an increase in the number of population caused an increase in demand for water for urban and agricultural purposes. The use of water with high salinity is one of the most likely options for meeting the needs. Sources of these waters are drainage water from irrigated agriculture, municipal wastewater and groundwater of poor quality.

Saltwater irrigation requires the use of additional water to leach salts from the root zone to prevent excessive salt accumulation, which would decrease crop yields. The risk of saline soils is always higher in soils with a fine texture than in soils with a large texture. This is due to the fact that sandy soils naturally have larger pores, which provide faster drainage [1-3].

The diffusion of any liquid, gas molecules from a low concentration to a high concentration of dissolved substances, which is facilitated by the presence of a semipermeable membrane, is called "osmosis". Osmosis is a natural phenomenon and an example of passive transport as a natural process that does not require additional energy for the movement of molecules.

Fertigation is a method of fertilizing plants by supplying dissolved minerals along with irrigation water. With the unreasonable use of fertigation, there is a potential danger of possible excessive salinization of the soil with subsequent negative effects on both plants and soil properties.
After fertigation, water added to the soil is used by plants or evaporates directly from the moist soil. In this case, salt remains in the soil. Subsequently, if it is not removed, salt will accumulate in the soil and this process is called salinization. Salinization means that the concentration of solute in the soil is higher than in the root. Due to the osmosis, water leaves the root system of plants and becomes less accessible for plants $[4,5]$.

Excessive salinity of the soil negatively affects both plants and soil properties. The response of cultivated crops to soil salinity is different. Some crops can produce crops with a very high level of soil salinity, while others are very sensitive to salinity, due to the fact that some crops are able to adapt to osmotic changes in such a way that allows them to extract more water from saline soil [3].

Any remediation of saline soils requires assessment and monitoring of salinity. Soil salinity is measured by electrical conductivity (EC) of the soil solution; water extracts of the soil (saturated paste or diluted aqueous extract from the soil 1: 5). Currently, this method requires direct soil sampling. The method can be used in various conditions, but its application depends on the collection of soil samples and methods of measurement (EC) of water soil extracts. Therefore, it is difficult to control the change in salt content over time with negligible spatial resolution, since the collection of soil samples is intrusive and disrupts the environment (soil structure and water flows). In addition, soil sampling is time consuming and often expensive.

Soil salinity can also be estimated indirectly by measuring volumetric electrical resistance $(\mathrm{ER}, \Omega \mathrm{m})$ or volumetric electrical conductivity ( $\mathrm{ECa}, \mathrm{dS} \mathrm{m}-1)$. The

Corresponding author: rail-1312@mail.ru 
development of proximal soil sensor systems and geophysical methods for measuring ECa or ER facilitates the collection of large data using less expensive, simpler and less time-consuming techniques. These sensors can be invasive, non-invasive or mounted on vehicles. In fact, it is desirable to use the least invasive method and a more advanced sensor to collect a large amount of data [6-8].

Another important factor associated with soil degradation and erosion is the stability of aggregates. Soil aggregates are groups of soil particles that bind to each other more strongly than adjacent particles. Soil resistance from external damaging effects of precipitation, runoff and wind is soil aggregate stability (WSA). In addition to the influence of external factors, stability of soil aggregates is influenced by many internal properties of the soil, for example, organic matter, texture, porosity, etc., as well as land use management $[9,10]$.

The aim of this study is to manage water and nutrients in the soil to maximize the efficiency of water and fertilizer use, as well as to minimize soil degradation.

The research objectives are to study the effect of fertigation on soil characteristics (studying the physicochemical characteristics of saline soils, stability of aggregates) and assess the leaching of salt from soil by rainfall.

\section{Materials and methods}

Experimental studies were conducted in in the western part, called Suchdol (Prague, the Czech Republic), on the campus of the Czech University of Natural Sciences, near the weather station; with geographical coordinates $50^{\circ} 8^{\prime} \mathrm{N}$ and $14^{\circ} 23^{\prime} \mathrm{E}$. The altitude is $286 \mathrm{~m}$, average annual temperature and precipitation are $9.1^{\circ} \mathrm{C}$ and 495 $\mathrm{mm}$, respectively, CET time zone (GMT +1 hour). The soil is a chernozem of loamy texture, it contains $22 \ldots$ $32.5 \%$ of sand, $39.5 \ldots 54 \%$ of silt and $22 \ldots 28 \%$ of clay. Field moisture capacity and the point of wilting are 34 and $21 \%$, respectively. Grass was sown in the spring of 2009 and has been maintained as a short lawn [11].

The total available water in the root zone is the difference between water content in the field moisture capacity and the wilting point. It was calculated as follows:

$$
T A W=1000\left(\theta_{f c}-\theta_{w p}\right) Z_{r}
$$

where $T A W$ - total available water in the root zone $(\mathrm{mm}) ; \theta_{\mathrm{fc}}-$ field water content, $\left(\mathrm{m}^{3} \mathrm{~m}^{-3}\right) ; \theta_{\mathrm{wp}}-$ water content in the wilting point, $\left(\mathrm{m}^{3} \mathrm{~m}^{-3}\right) ; \mathrm{Z}_{\mathrm{r}}-$ root depth (mm).

The experimental field was divided into four sections with four types of fertigation procedures:

1. Fertigation with nutrient solution $\mathrm{A}(\mathrm{EC}=1 \mathrm{mS}$ / $\mathrm{cm}, \mathrm{pH}=6$ ).

2. Fertigation with nutrient solution $\mathrm{B}(\mathrm{EC}=2 \mathrm{mS} /$ $\mathrm{cm}, \mathrm{pH}=6$ ).

3. Irrigation with tap water without any fertilizers $(\mathrm{EC}=274 \mathrm{mS} / \mathrm{cm}, \mathrm{pH}=6.5)$.
4. Control plot (grown on a hillock where fertilizers and irrigation were not used).

Fertigation was used with solutions at a high salt concentration in three experimental sites, and in the fourth site, the following model was used: FS-DSS using nutrient solution -NPK, $\mathrm{Ca}, \mathrm{Mg}$ and trace elements.

Figures $\mathbf{1}$ and $\mathbf{2}$ illlustrate the ECH2O system (sensors, data loggers, and software). The sensors installed in the soil are of 5TE type, they perform three measurements (volumetric water content, temperature and EC) and determine the volumetric water content (VWC) by measuring the dielectric constant of the medium using capacitive / frequency technology. Six sensors are installed at a depth of $20 \mathrm{~cm}$, two for each section. Two Em50 electronic data loggers were used with ECH2O software to configure and download the Excel data with a measurement interval of one hour.

Weather data were monitored daily at Suchdol Weather Station using TightVNC, a remote control software package. The daily evapotranspiration was evaluated using DSS-FSS, which works according to the modified FAO Penman-Monteith equations [4,12].

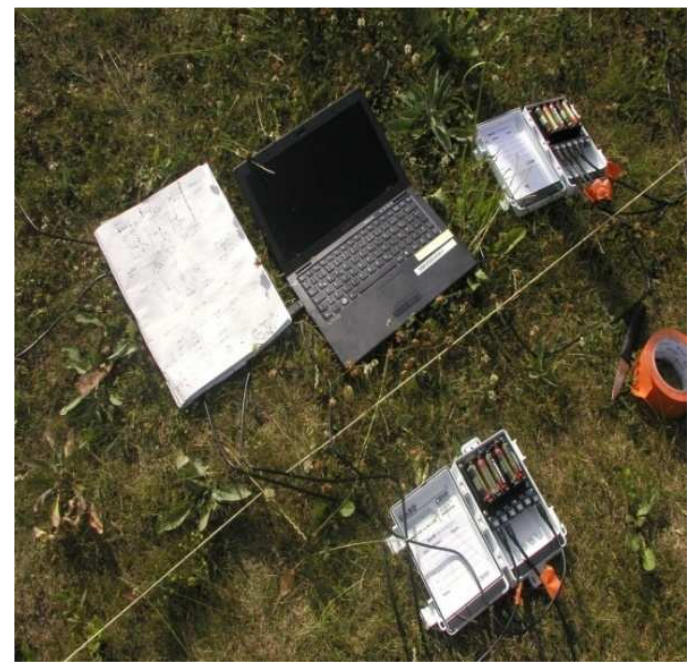

Fig. 1. Data Loggers DecagonEm50

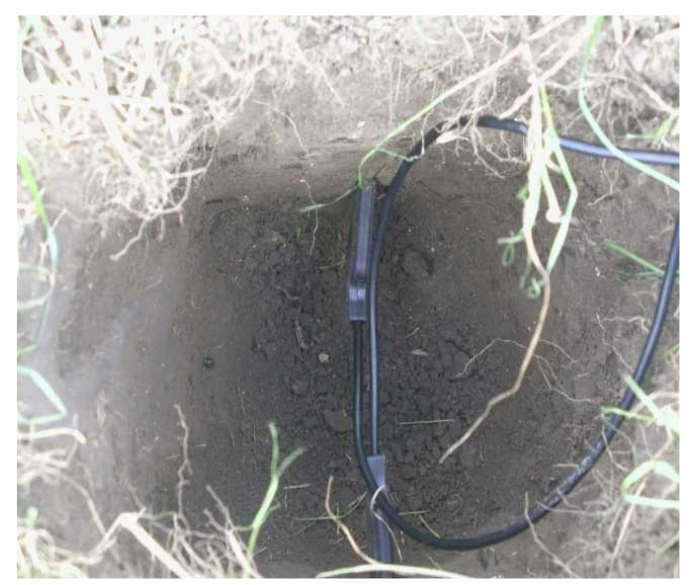

Fig. 2. Sensors for monitoring soil moisture / salinity

To study the effect of soil desalination by reducing salinity by leaching and changing its physical properties, six soil samples (three ones from a depth of $10 \mathrm{~cm}$ and three ones from a depth of $20 \mathrm{~cm}$ ) were taken from each 
plot in September, November and January. Samples were taken to estimate the total dry weight.

The quantitative value of the total soil salinity was measured by conductivity of the soil ethanol extract. The content of water-stable aggregates (WSA) was measured by screening device 12 (Diaz-Zoritaetal., 2002 and DIN 19683-16) [10] (Fig. 3.).

$$
W S A=\frac{W d s}{W d s+W d w},
$$

where WSA is the index of waterproof (stable) aggregates (-); Wds - weight of dispersed aggregates in dispersing solution $(г)$; Wdw - weight of dispersed aggregates in distilled water $(\mathrm{g})$.

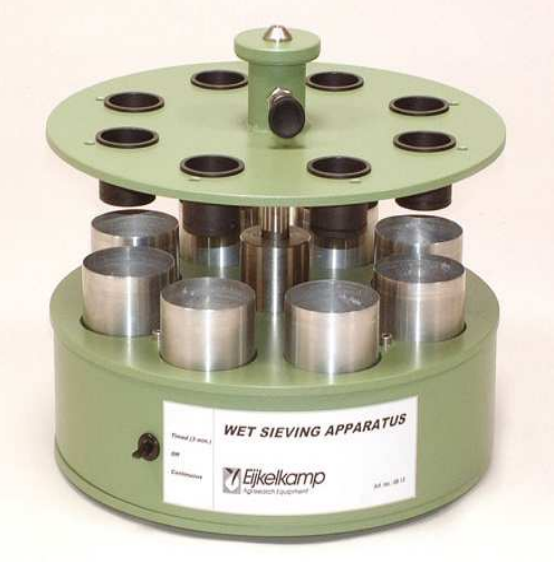

Fig. 3. Wet Screener

\section{Results and Discussion}

The results showed that electrical conductivity of the soil (EC) does not significantly differ from that of the site, which means that the difference between the EC values for different fertigation methods at two depths varies slightly with time $(p=0.173>0.05)$ (the effect of desalination by rain) (Fig. 5., Fig. 6.).

The index of water-resistant aggregates for all plots showed some improvement in plots A (high salinity fertigation) and $C$ (simple irrigation without feeding) throughout the entire experimental period. None of the three fertigation procedures showed a lower WSA value than in the control plot at the end of the experimental period (Fig. 7., Fig. 8.).

Monitoring of the EC soil using the Decagon ECH2O system and 5TE sensors shows that the soil EC varied between classes of soils without salinization and slightly saline soils (according to the USDA classification) [13, 14]. At the end of the experimental period, all the areas showed a lack of salinity (Fig. 4.).

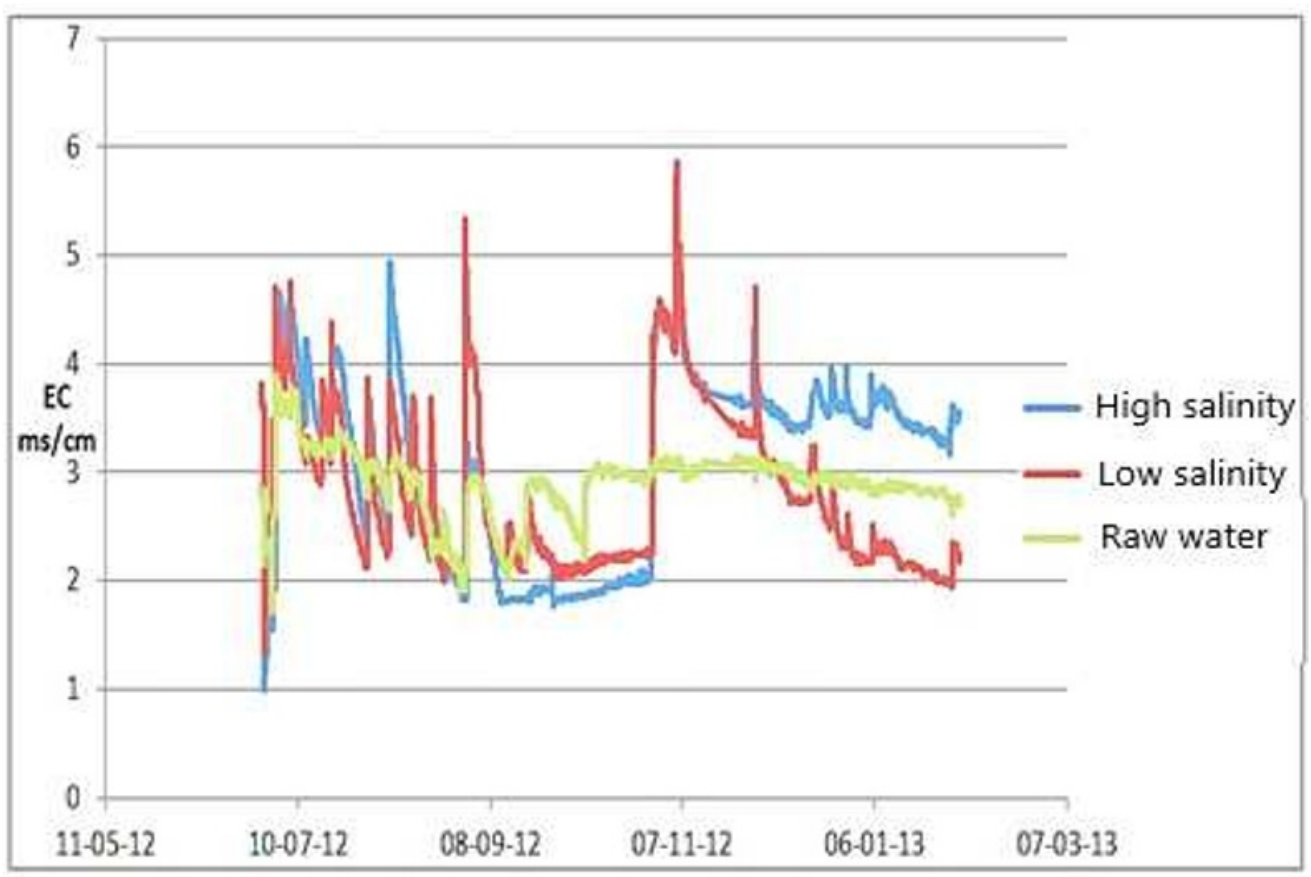

Fig. 4. Change in conductivity of soil solution over time; average sensor values (two sensors in each treatment) 


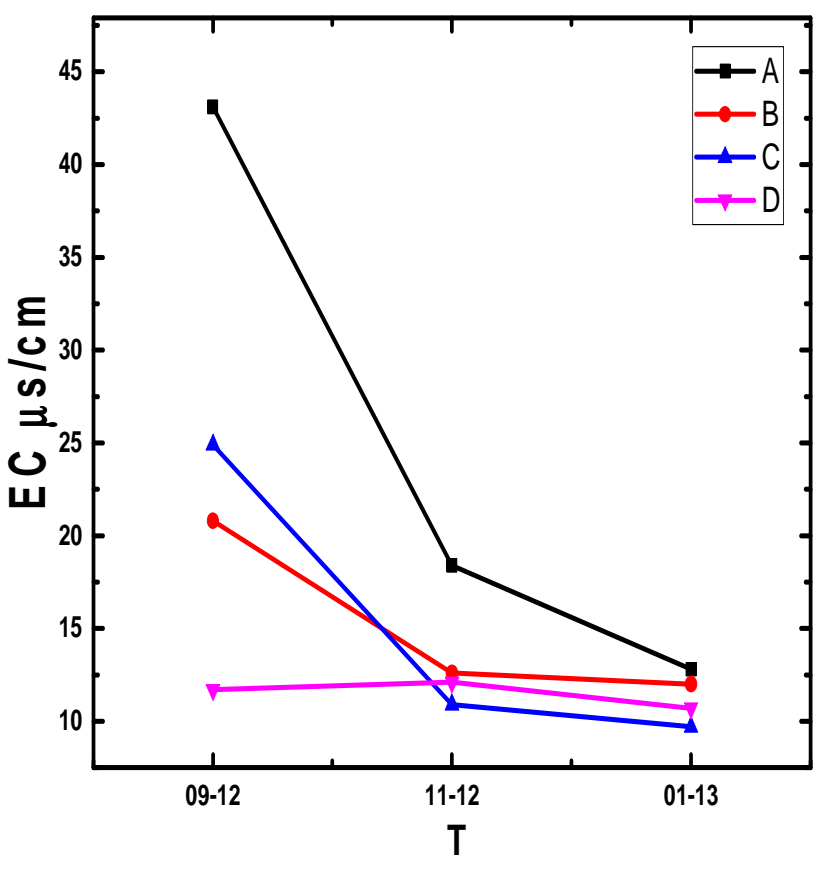

Fig. 5. EC at a depth of $10 \mathrm{~cm}$ (A- high salinity, B- low salinity, C- raw water, D- control)

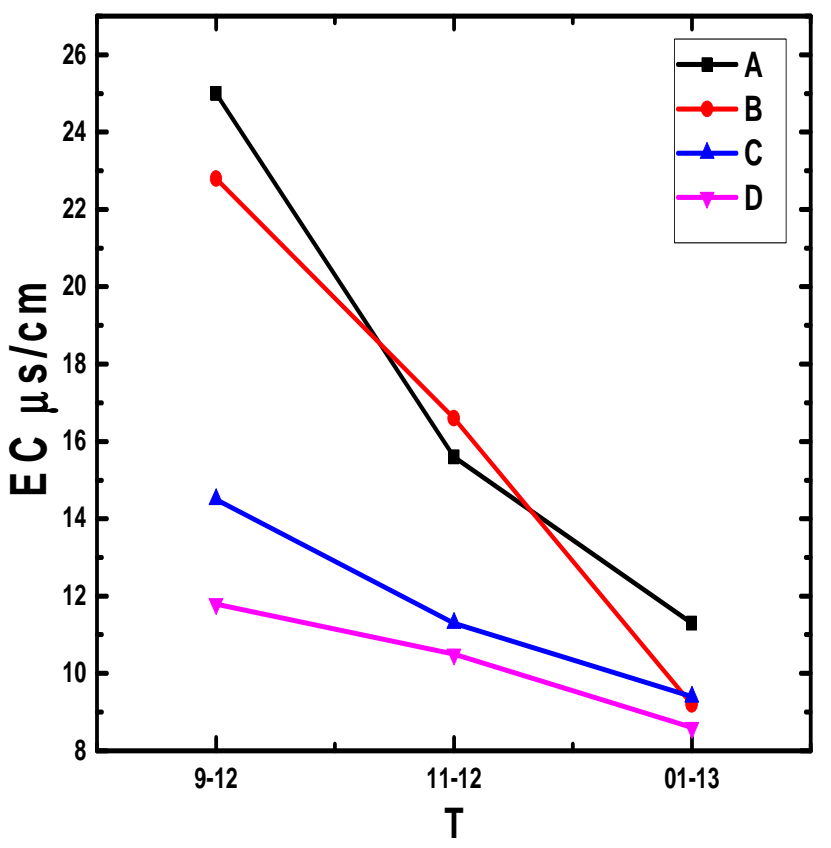

Fig. 6. EC at a depth of $20 \mathrm{~cm}$ (A- high salinity, B- low salinity, C- raw water, D- control)

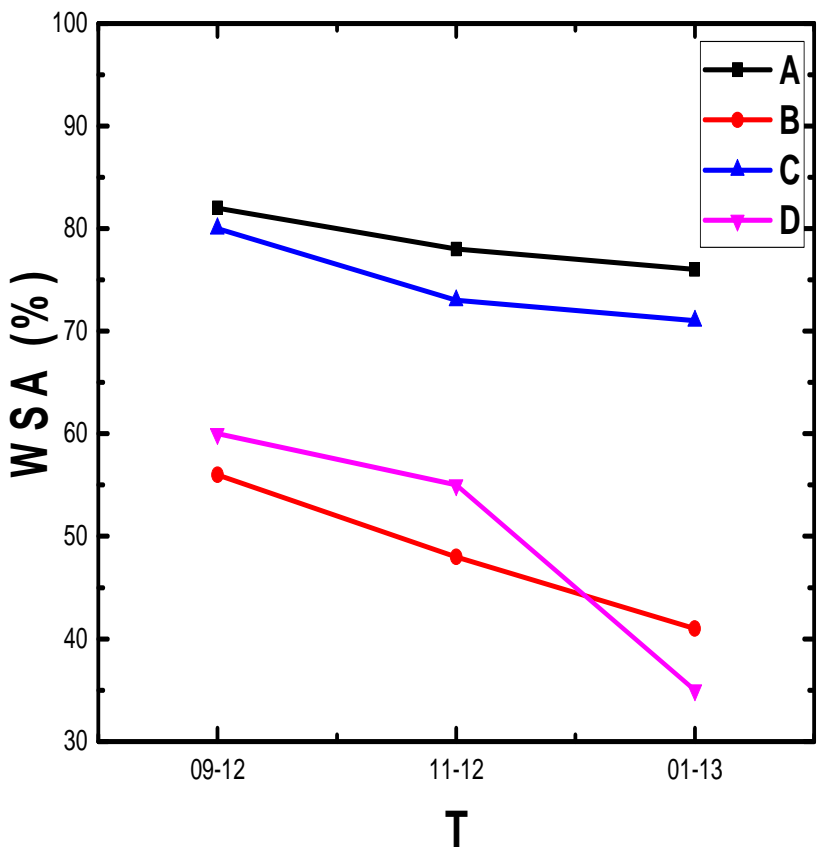

Fig. 7. WSA at a depth of $10 \mathrm{~cm}$ (A- high salinity, B- low salinity, C- raw water, D- control)

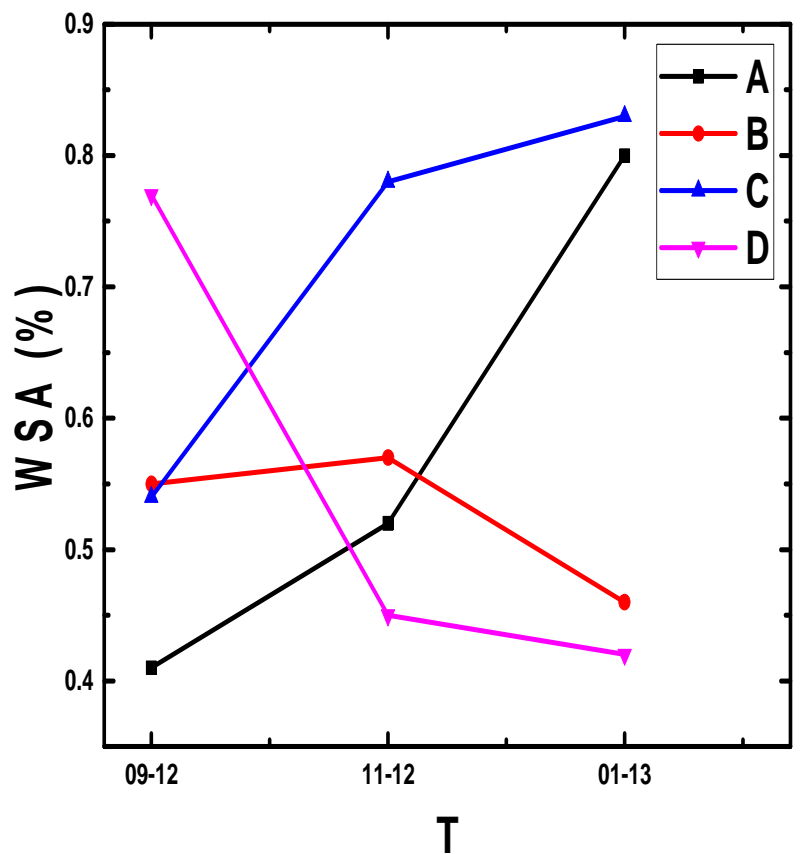

Fig. 8. WSA at a depth of $20 \mathrm{~cm}$ (A- high salinity, B- low salinity, C- raw water, D- control) 


\section{Conclusion}

Increased soil salinization by fertigation methods is caused by rising costs of fresh water, which led to the use of salt water for irrigation purposes.

Fertigation can cause soil salinization, as plants absorb the nutrients and water that remained after evaporation, and the rest of the salt remaining in the soil begins to accumulate.

Our study focused on the effects of fertigation on soil salinization and the content of water-stable aggregates. It was revealed that the soil EC varied between soil classes without salinization and slightly saline (according to the USDA classification). At the end of the experimental period, all areas showed a lack of salinity.

\section{References}

1. A.Kh. Abdelfattah, I.M. Gomaa., D.T. Khaliullin, Energy efficient use of water resources in agriculture, Agroengineering science of the 21st century: Proceedings of the regional scientificpractical conference, 416, 335-339 (Kazan State Agrarian University publishing house, 2018)

2. D.I. Fayzrakhmanov, F.T. Nezhmetdinova, B.G. Ziganshin, A.R. Valiev, Food Safety in the WTO, Rural Machine Operator, 11(57), 4-6 (2013); A. Capra, B. Scicolone, Recycling of poor-quality urban waste water by drip irrigation systems, J. Cleaner Prod., 15, 1529-1534 (2007)

3. J.M. Moreira Barradas, S. Matula, F. Dolezal, A decision support system-fertigation simulator (DSSFS) for design and optimization of sprinkler and drip irrigation systems, Comput. Electron. Agric., 86, 111-119 (2012)

4. R. Sabirov, A. Valiev, L. Karimova, A. Dmitriev, D. Khaliullin, Influence of physical factors on viability of microorganisms for plant protection, Engineering for Rural Development, 18 (2019) 10.22616/ERDev2019.18.N211
5. V. Adamchuk, R. ViscarraRossel, Development of on-the-go proximal soil sensor systems, in: Proximal soil sensing, R. ViscarraRossel, A. McBratney, B. Minasny, eds., 15-28 (Springer, Netherlands, 2010)

6. I.G. Galiev, K.A. Khafizov, N. Adigamov, R.K. Khusainov, Increase of efficiency of tractors use in agricultural production, 17th International Scientific Conference Engineering for Rural Development Proceedings, 17, 373-377 (2018)

7. D.L. Corwin, S.M. Lesch, Application of soil electrical conductivity to precision agriculture: Theory, principles, and guidelines, Agron. J., 95(3), 455-471 (2003)

8. B. Barthes, E. Roose, Aggregate stability as an indicator of soil susceptibility to runoff and erosion: Validation at several levels, Catena, 47(2), 133-149 (2002)

9. M. Diaz-Zorita, E. Perfect, J.H. Grove, Disruptive methods for assessing soil structure, Soil Till. Res., 64, 3-22 (2002)

10. M. Miháliková, S. Matula, F. Doležal, HYPRESCZ-Database of 440 soil hydrophysical properties in the Czech Republic, Soil Water Res., 441(8), 34-41 (2013)

11. R.G. Allen, L.S. Pereira, D. Raes, M. Smith, Crop evapotranspiration: Guidelines for computing crop water requirements: FAO Irrigation and drainage paper 56, 328 (Food and Agriculture Organization, Rome, 1998)

12. A. Valiev, I. Mukhametshin, F. Muhamadyarov, F. Yarullin, G. Pikmullin, Theoretical substantiation of parameters of rotary subsoil loosener, 18th International Scientific Conference Engineering for Rural Development Proceedings, 18, 312-318 (Latvia University of Life Sciences and Technologies Faculty of Engineering, Jelgava, 2019)

13. Agriculture handbook no. 60-Riverside, Diagnosis and improvement of saline and alkali soils, CA. (USDA Salinity Laboratory, 1969) 